\title{
Study on Control of Wall Deflection in Earth Stepped-Twin Retaining Wall Using Anchor Method by means of Numerical Simulation
}

\author{
Kazuki Maehara $\mathbb{D}^{1},{ }^{1}$ Akihiro Hamanaka $\mathbb{D}^{1},{ }^{1}$ Takashi Sasaoka, ${ }^{1}$ Hideki Shimada $\mathbb{D}^{1}{ }^{1}$ \\ and Seiya Sakuma ${ }^{2}$ \\ ${ }^{1}$ Department of Earth Resources Engineering, Faculty of Engineering, Kyushu University, Fukuoka 819-0395, Japan \\ ${ }^{2}$ Aoyama Kiko Co., Ltd., Tokyo 110-0014, Japan \\ Correspondence should be addressed to Akihiro Hamanaka; hamanaka@mine.kyushu-u.ac.jp
}

Received 11 November 2019; Revised 27 December 2019; Accepted 31 December 2019; Published 23 January 2020

Academic Editor: Wayne Yu Wang

Copyright (c) 2020 Kazuki Maehara et al. This is an open access article distributed under the Creative Commons Attribution License, which permits unrestricted use, distribution, and reproduction in any medium, provided the original work is properly cited.

\begin{abstract}
The demand for specific earth retaining wall methods is increasing along with the advancement and overcrowding of underground space use such as the presence of adjacent structures in an urban area. To cope with this, the method named earth stepped-twin retaining wall is increasingly being applied. However, there is a concern about the workplace if the earth pressure causes a heaving and pressing phenomenon from both ends of the retaining wall in the earth stepped-twin retaining wall. Therefore, we proposed the application of an anchor method that contains the inner and outer walls by using numerical simulation. The effects of the difference in soil properties, the horizontal distance between the outer and inner walls, and the depth of the outer wall embedment on the anchor were investigated. The results of this study show that the wall deflection of the inner wall could improve by adopting the anchor support. Besides, it was found that the inner wall can be efficiently suppressed by adopting the hybrid system with anchors and struts according to the soil properties, horizontal distance, and the depth of the outer wall.
\end{abstract}

\section{Introduction}

Congestion of underground structures occurs with the increase of utilization in the underground space in urban areas. The open-cut method is a construction approach for making an open trench to build the water and sewage systems, electrical equipment, and gas pipelines. This method is also adopted to provide the starting/arrival shaft for the trenchless technologies such as shield method and pipe jacking method, and to construct underground spaces that can be used such as the basement of the building and the subway station. In the open-cut method, the retaining wall has to be introduced to prevent the collapse of the surrounding ground when the geotechnical condition of the ground is weak. The design of appropriate retaining wall and support system attributes to reduce excavation-induced deformation is critical. Studies of retaining walls have been conducted such as the prediction of lateral earth pressure and deformation behavior by using laboratory experiments and numerical simulation $[1,2]$, the introduction of reinforced materials $[3,4]$, and new design of the retaining wall [5]. Additionally, several researchers investigated the optimization of the retaining wall design from an economical and geotechnical point of view $[6,7]$. The braced excavation with struts is one of the typical constructions to ensure the reliability of structure systems in the deep excavation. Many kinds of research were found to discuss the prediction of the excavation behavior, strut forces, and preloading in deep excavation by comparing with the results of numerical analysis and measurement data in the field [8-14]. However, the dense arrangement of struts could obstruct construction works and increase the cost and construction period because of insufficient working space. Therefore, the strut-free retaining wall system was studied in several studies [15-17]. 
One of the alternative methods to the braced excavation is a tied-back retaining wall system in which the anchor support systems are commonly used to reduce the wall deflection of the wall [18]. The use of tieback anchors was also investigated for slope reinforcement to decrease the risk of slope slide [19-21]. The design and construction of the retaining wall with tieback anchors for deep excavation in the civil engineering field were discussed in previous studies [22-25]. The research of numerical methods about the retaining using wall and anchor was studied [26, 27].

Recently, the method named earth stepped-twin retaining wall is found with the diversification to utilize the underground spaces. The earth stepped-twin retaining wall is one of the methods applied when the height of the foundation bottom of the structure is different in a plane or when the existing structure is buried under the ground [28]. A schematic diagram of the earth stepped-twin retaining wall is shown in Figure 1. As shown in Figure 1 [29], the outer and inner walls are constructed to prevent the collapse of the surrounding ground. The earth stepped-twin retaining wall has advantages to reduce the amount of excavation and the steel material of earth retaining support because it is not necessary to excavate unnecessary parts. Examples of applications include constructions, e.g., the excavation depth differs depending on the shape of the underground structure, and the temporary working spaces are needed because of the absence of plants and materials on the surface. The countermeasures have to be considered against rebound by buffer excavation. Several kinds of research are found to discuss the difference of deformation behavior and stress condition compared with the conventional retaining wall and the effect of the horizontal distance between the outer and inner walls and the depth of the outer wall embedment on the displacement of the inner wall $[29,30]$.

However, there are only limited studies about the earth stepped-twin retaining wall involving the tieback anchors. The challenge of this study is how the sufficient working space can be secured in the inner wall by adopting the new concept of anchor methods. Additionally, there is concern about the stability of the working space if the earth pressure causes heaving and pressing phenomenon from both ends of the retaining wall in the earth stepped-twin retaining wall under the deep excavation. Therefore, this study investigates the application of the anchor support as a new construction method of earth stepped-twin retaining wall by numerical simulation.

\section{New Concept of Earth Stepped-Twin Retaining Wall with Anchor Support}

The role of the anchors is to restrain the inner and outer walls in the earth stepped-twin retaining wall. The free length and anchorage of the anchor are usually long in the tieback anchor system to reduce the wall deflection of the retaining wall. However, the length of the anchor is limited in the inner wall of the earth stepped-twin retaining wall because the embedded part of the outer wall is an obstacle. Therefore, the present study suggests that the anchors should be hooked in the embedded part of the outer wall as shown in Figure 2.

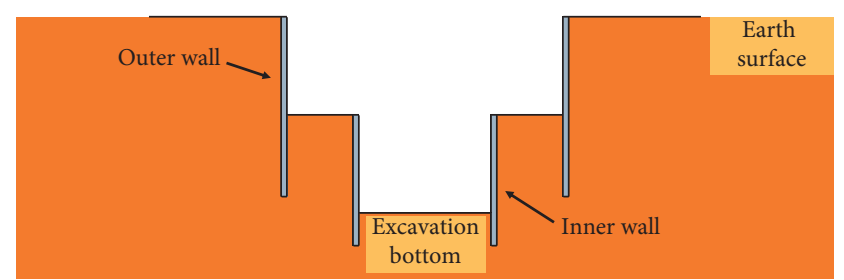

FIGURE 1: Schematic diagram of earth stepped-twin retaining wall.

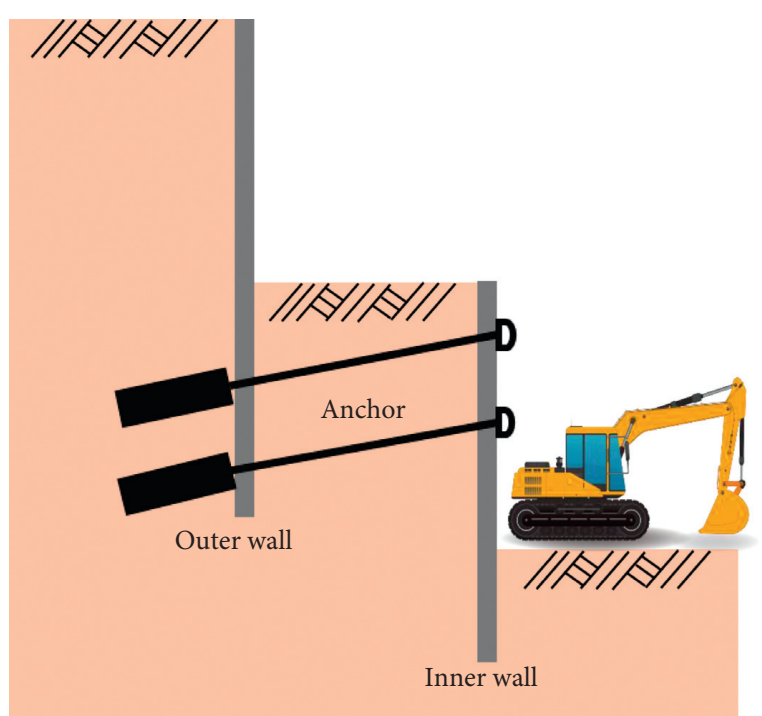

FIGURE 2: Image of anchor construction (cross section).

In this case, the restraint force can be applied to the anchor between the inner and outer walls by introducing prestress in anchor construction because the anchors can be mechanically fixed to the outer wall. As a result, the deformation of the inner wall can be constrained and suppressed. There is a concern that it is affected by grout bleeding and residual slime if the anchor is installed in the horizontal direction in actual construction. Therefore, in this study, the installation angle of the anchor is $5^{\circ}$ downward as recommended by the Japan Society of Civil Engineers [31]. The anchor type is assumed to be 7 stands of PC steel and the type B.

\section{Numerical Modelling}

Two-dimensional finite element method (FEM) analysis based on Phase ${ }^{2}$ ver6.0 is used for numerical analysis of earth stepped-twin retaining wall. The optimum mesh size was determined when the deformation of the inner wall converged. An elastic model is used as material models in the analyses. In this analysis, only half of the excavation model was developed because of symmetrical conditions, and the excavation sequence was simulated by adopting step analysis with consideration of the construction process. Weight analysis was performed in the first step, and the outer wall was constructed in the next step. Next, the excavation to the bottom of the outer wall and the installation of the strut were repeated in sequence, excavating to a depth of $20 \mathrm{~m}$, and 7 
struts were constructed, as shown in Figure 3. The inner wall was constructed in the subsequent step, and the excavation to the bottom of the inner wall and installing of the anchor were repeated in sequence. Finally, excavation was done to a depth of $30 \mathrm{~m}$, and 6 anchors were installed. The geometry of the analysis model is shown in Figure 4 [29]. We focused on the results of the displacement of the inner wall after these analysis steps in this study. The braced excavation is adopted in the outer wall, and the tieback anchors system is adopted in the inner wall to observe the effectiveness of anchors in reducing the wall deflection in the inner wall. The beam elements are used for earth retaining walls and struts. Additionally, a joint element is provided to consider the friction between the ground and the earth retaining wall as discussed by Honda [32]. The input physical properties of joint element are shown in Table 1. The input physical properties of soil, earth retaining wall and struts, and anchors used in this analysis are shown in Tables $2-4$ as discussed in other pieces of the literature [33-35]. Horizontal and vertical spacing of the struts is $3.0 \mathrm{~m}$, whereas those of anchors were $1.5 \mathrm{~m}$ and $1.0 \mathrm{~m}$, respectively. The analysis model in Figure 4 is created based on a general construction site in Japan. Additionally, prestress is adopted in anchor construction. As a procedure for determining the prestress value, the axial force of the anchor is calculated in the numerical simulation, and $60 \%$ of this value $(180 \sim 270 \mathrm{kN})$ is introduced into each anchor as prestress.

\section{Results and Discussion}

4.1. Comparison of Anchor Method and Braced Excavation. Figure 5 shows the inner wall deflection during the final excavation when neither the anchors are installed nor the strut is constructed, when the anchors are installed without constructing the strut on the inner wall, when the strut is constructed without installing the anchors on the inner wall, and when both the anchors are installed and the strut is constructed. As shown in the figure, the maximum horizontal displacement is $113 \mathrm{~mm}$ when the anchor is not installed, whereas it is $88 \mathrm{~mm}$ when the anchor is installed and $36 \mathrm{~mm}$ when the strut is installed. This result means that the wall deflection of the inner wall can improve by adopting the anchor support system such that the anchors are hooked in the embedded part of the outer wall although the braced excavation with the struts is more effective to reduce the wall deflection. Considering that the displacement of the retaining wall in urban civil engineering is generally kept within $70 \mathrm{~mm}$ in the Japanese construction site, the displacement suppressing effect in the anchor is insufficient. Therefore, we investigated how to effectively suppress the inner wall by adopting the hybrid system with anchors and struts.

4.2. Hybrid System with Anchors and Struts. The case studies are conducted based on the construction status of both the anchors and struts. In other words, assuming three cases as shown in Figures 6(a)-6(c), the number of struts is changed to 1,2 , and 3. The structural drawing in Figure 6 is explained in Figure 7 as numerical model. In addition, the influence on

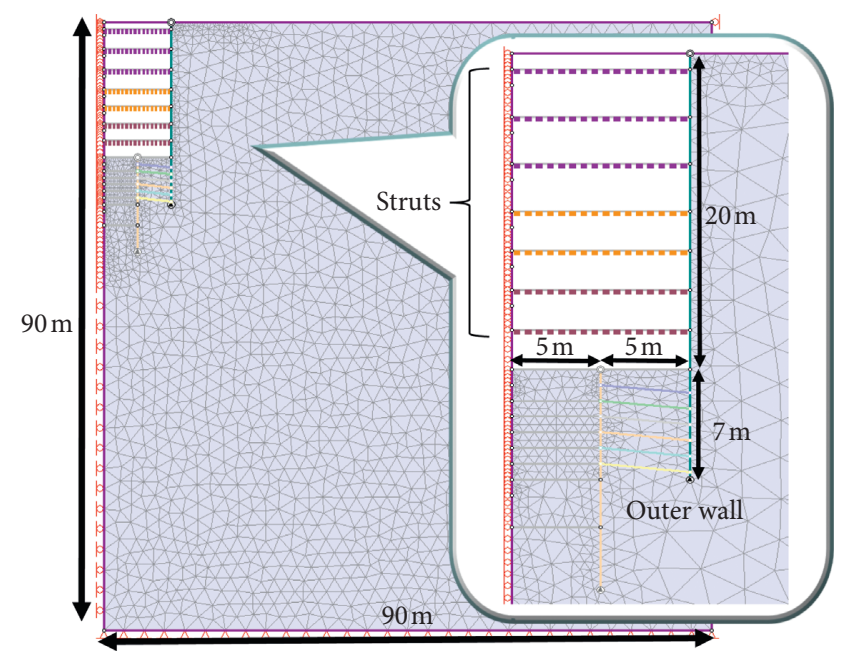

FIgURE 3: Analysis step constructing the outer wall and installing the 7 struts.

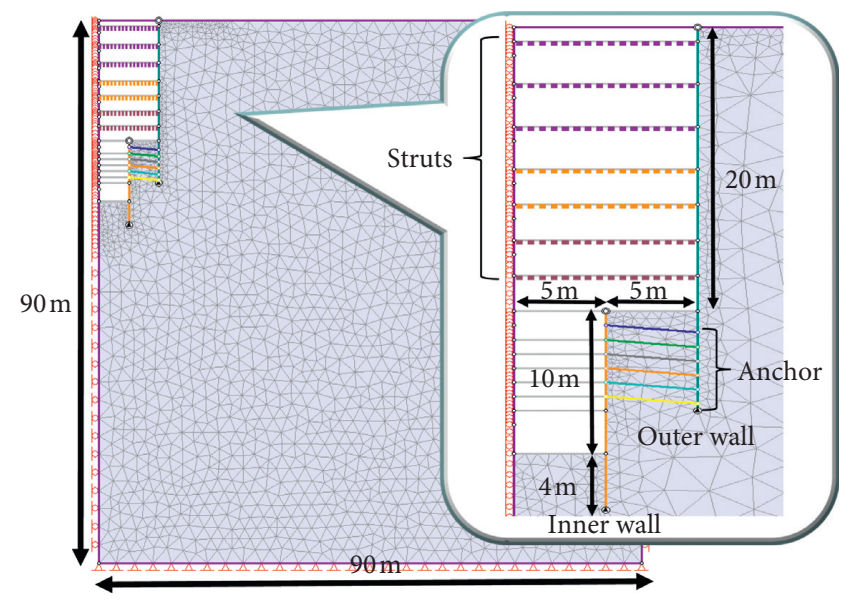

FIgURE 4: Geometry of earth stepped-twin retaining wall.

Table 1: Physical and mechanical properties of joint element.

\begin{tabular}{lcccc}
\hline & $\begin{array}{c}\text { Normal } \\
\text { stiffness, } k_{n} \\
(\mathrm{MPa} / \mathrm{m})\end{array}$ & $\begin{array}{c}\text { Shear } \\
\text { stiffness, } k_{s} \\
(\mathrm{MPa} / \mathrm{m})\end{array}$ & $\begin{array}{c}\text { Internal } \\
\text { friction } \\
\text { angle, } \varphi\left(^{\circ}\right)\end{array}$ & $\begin{array}{c}\text { Cohesion, } c \\
(\mathrm{MPa})\end{array}$ \\
\hline $\begin{array}{l}\text { Joint } \\
\text { element }\end{array}$ & 5,000 & 10 & 0 & 0.15 \\
\hline
\end{tabular}

the hybrid system with anchors and struts due to changes in soil properties, the horizontal distance between the outer wall and the inner wall, and the depth of the outer wall embedment are investigated. These case studies are also conducted to determine the number of struts and anchors that efficiently restrains the inner wall deflection.

4.2.1. Influence of Soil Properties. Case studies in $N$-value (sandy soil: 5 to 50 and cohesive soil: 3 to 35 ) obtained from the standard penetration test are also used with a relation of $E=700 \mathrm{~N}\left(\mathrm{kN} / \mathrm{m}^{2}\right)$ as discussed by the Japanese Geotechnical Society [36]. E indicates the modulus of deformation. Table 5 shows the input physical properties of sandy and 
TABLe 2: Physical and mechanical properties of soil.

\begin{tabular}{lccccc}
\hline & $\begin{array}{c}\text { Unit weight, } \gamma \\
\left(\mathrm{MN} \cdot \mathrm{m}^{3}\right)\end{array}$ & $\begin{array}{c}\text { Modulus of deformation, } E \\
(\mathrm{MPa})\end{array}$ & $\begin{array}{c}\text { Poisson's ratio, } v \\
(-)\end{array}$ & $\begin{array}{c}\text { Internal friction angle, } \varphi \\
\left({ }^{\circ}\right)\end{array}$ & $\begin{array}{c}\text { Cohesion, } c \\
(\mathrm{MPa})\end{array}$ \\
\hline $\begin{array}{l}\text { Cohesive } \\
\text { soil }\end{array}$ & 0.014 & 25 & 0.40 & 0 & 0.15 \\
\hline
\end{tabular}

TABLE 3: Physical and mechanical properties of earth retaining wall and struts.

\begin{tabular}{lcccc}
\hline & $\begin{array}{c}\text { Young's modulus, } E \\
(\mathrm{GPa})\end{array}$ & $\begin{array}{c}\text { Poisson's ratio, } v \\
(-)\end{array}$ & $\begin{array}{c}\text { Cross-sectional area, } A \\
\left(\mathrm{~cm}^{2}\right)\end{array}$ & $\begin{array}{c}\text { Geometrical moment of inertia, } I \\
\left(\mathrm{~cm}^{4}\right)\end{array}$ \\
\hline Outer wall SMW & 200 & 0.30 & 187.2 & 114,000 \\
Inner wall sheet pile & 200 & 0.30 & 267.6 & 63,000 \\
$1^{\text {st }}, 2^{\text {nd }}$, and 3 & 200 & 0.30 & 34.9 & 5,767 \\
struts & 200 & 0.30 & 51.6 & 11,667 \\
$4^{\text {th }}$ and $5^{\text {th }}$ struts & 200 & 0.30 & 65.9 & 19,667 \\
$6^{\text {th }}$ and $7^{\text {th }}$ struts & & & \\
\hline
\end{tabular}

TABLe 4: Physical and mechanical properties of anchors.

\begin{tabular}{lcccc}
\hline & Diameter $(\mathrm{mm})$ & Cross-sectional area $\left(\mathrm{mm}^{2}\right)$ & Mass per unit length $(\mathrm{kg} / \mathrm{km})$ & Maximum tensile stress $(\mathrm{kN})$ \\
\hline 7 stands of PC steel & 12.7 & 98.71 & 774 & 183 \\
\hline
\end{tabular}

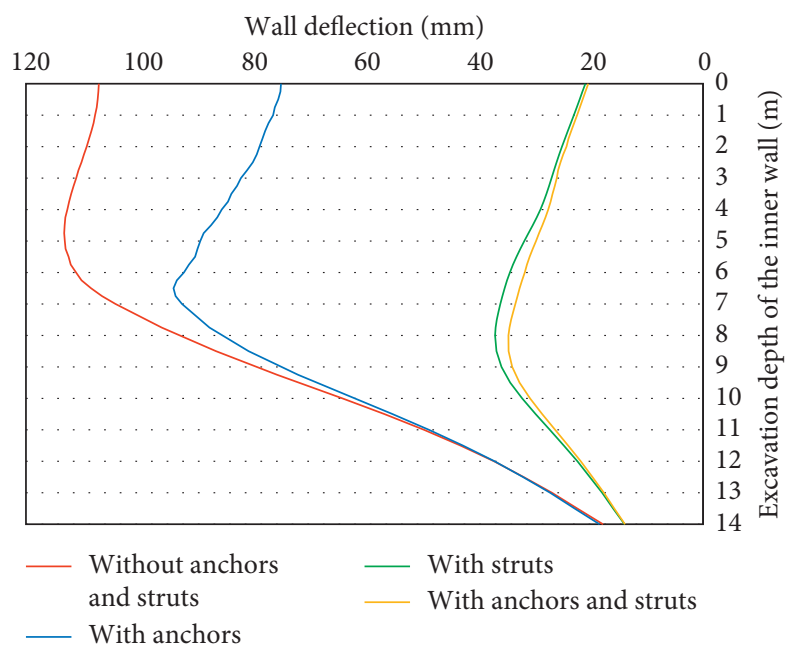

FIGURE 5: Comparison of inner wall deflection.

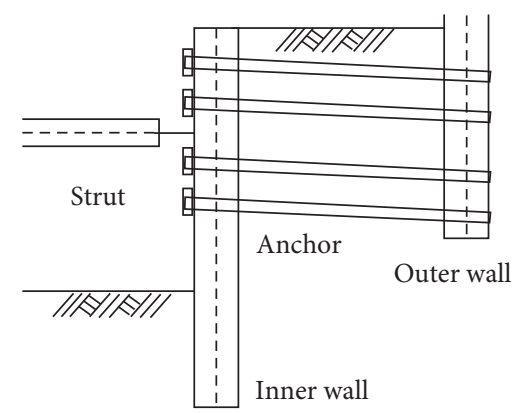

(a)

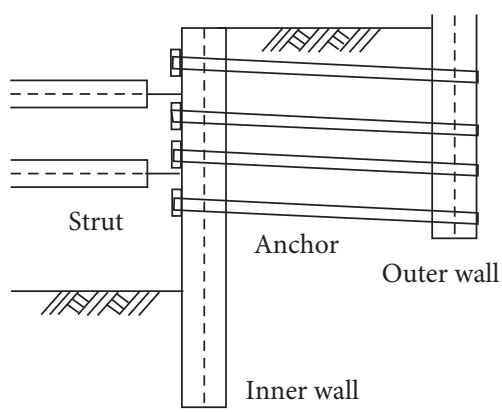

(b)

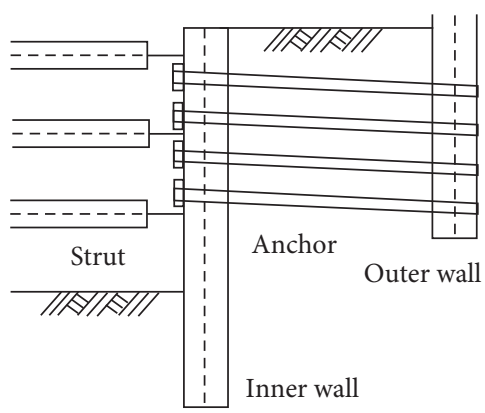

(c)

FIGURE 6: Structural drawing in earth stepped-twin retaining wall by constructing with anchors and struts. (a) 1 strut. (b) 2 struts. (c) 3 struts. 


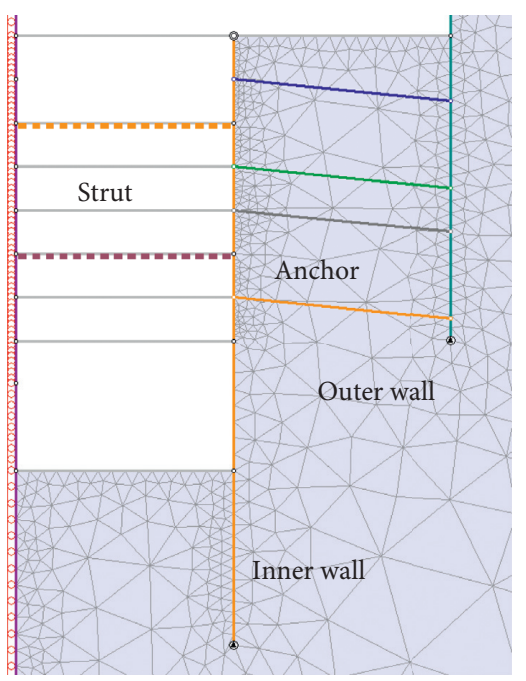

(a)

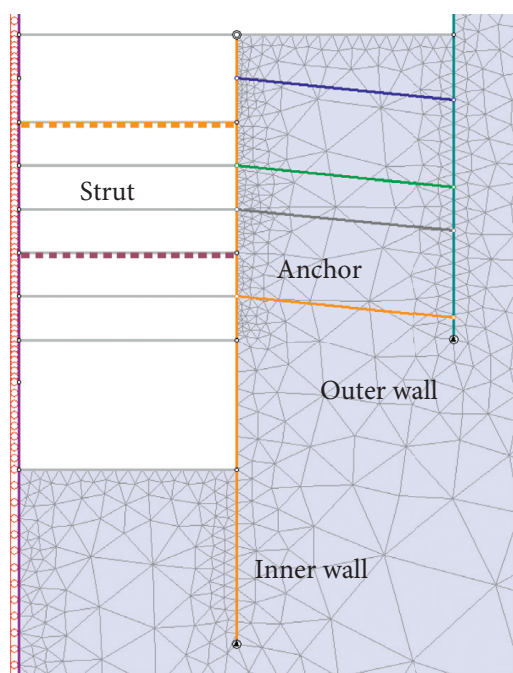

(b)

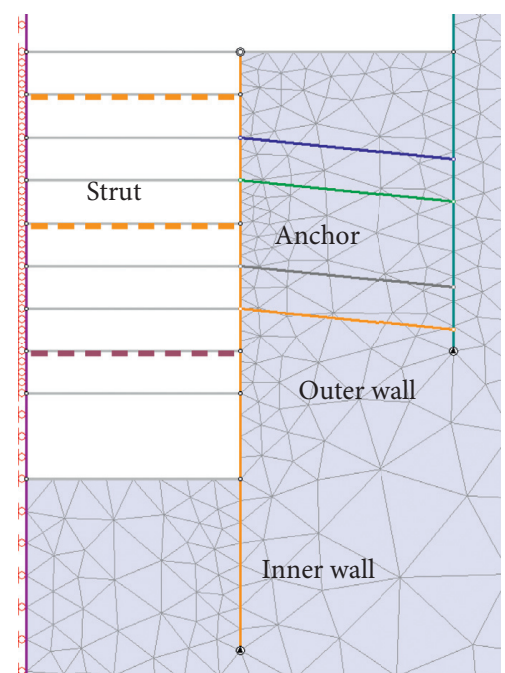

(c)

FIGURE 7: Numerical model in earth stepped-twin retaining wall by constructing with anchors and struts. (a) 1 strut. (b) 2 struts. (c) 3 struts.

TABle 5: Physical and mechanical properties of sandy soil and cohesive soil.

\begin{tabular}{|c|c|c|c|c|c|}
\hline & $\begin{array}{l}\text { Unit weight, } \gamma \\
\left(\mathrm{MN} \cdot \mathrm{m}^{3}\right)\end{array}$ & $\begin{array}{l}\text { Modulus of deformation, } E \\
(\mathrm{MPa})\end{array}$ & $\begin{array}{c}\text { Poisson's ratio, } v \\
(-)\end{array}$ & $\begin{array}{c}\text { Internal friction angle, } \varphi \\
\left({ }^{\circ}\right)\end{array}$ & $\begin{array}{c}\text { Cohesion, } c \\
(\mathrm{MPa})\end{array}$ \\
\hline Sandy soil & 0.017 & $3.5,7,14,21,35$ & 0.30 & 35 & 0 \\
\hline $\begin{array}{l}\text { Cohesive } \\
\text { soil }\end{array}$ & 0.014 & $2.1,7,10.5,14,25$ & 0.40 & 0 & 0.15 \\
\hline
\end{tabular}

cohesive soil used in this study. Figure 8 shows the relationship between the $\mathrm{N}$-value and the maximum horizontal displacement of the inner wall during the final excavation. First, it can be seen that as the number of struts increases, the maximum horizontal displacement of the inner wall during the final excavation is suppressed. This is because the deformation of the inner wall is suppressed by the struts. It can also be observed that the maximum horizontal displacement of the inner wall decreases as the $\mathrm{N}$-value increases. This is because the excavation-induced deformation is reduced with the increases of the modulus of deformation as the $\mathrm{N}$-value increases. Furthermore, we focused on a guideline for controlling the displacement of the earth retaining wall in urban civil engineering to within $70 \mathrm{~mm}$. According to this guideline, it is possible to reduce to the guideline by constructing 2 struts and 4 anchors when the $N$-value of sandy soil is 20 30, and when the cohesive soil is 15 20. Additionally, it is possible to suppress the guideline by constructing 1 strut and 4 anchors when the $N$-value of the sandy soil is 50 and the cohesive soil is 35 . In this way, it is thought that the deformation of the outer wall can be efficiently suppressed by determining the appropriate number of anchors and struts to be installed according to the $N$-value of the ground.

4.2.2. Influence of Horizon Distance between the Outer Wall and the Inner Wall. Figure 9 shows the maximum amount of horizontal displacement of the inner wall during the final excavation when the horizon distance between the outer and

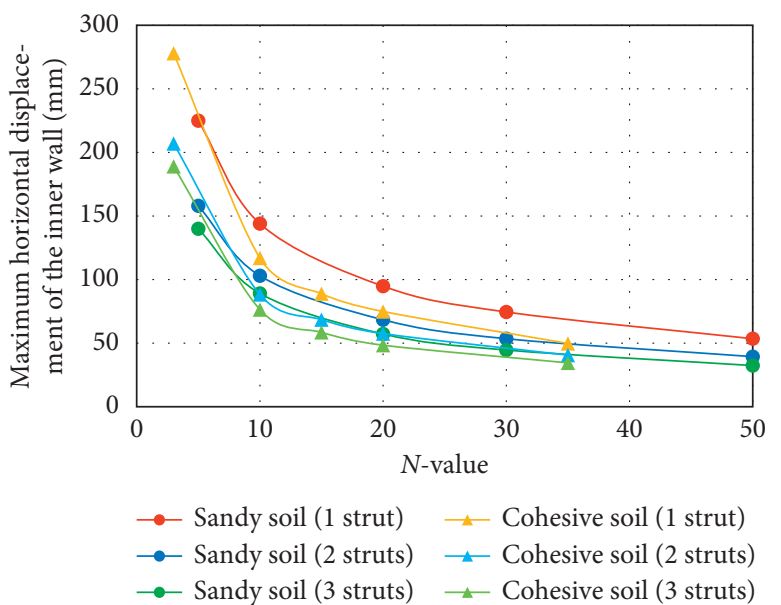

FIGURE 8: Relationship between $N$-value of sandy soil and cohesive soil and maximum horizontal displacement of the inner wall.

inner walls is changed from $3 \mathrm{~m}$ to $7 \mathrm{~m}$ in the clay of $N$-value 15. The figure shows that as the horizontal distance between the outer and inner walls decreases, the maximum horizontal displacement of the inner wall increases. According to the tunnel standard specification document discussed by the Japan Society of Civil Engineers [31], the lateral pressure acting on the inner wall in the earth stepped-twin retaining wall method is different depending on the buffer distance between the inner and outer walls. Therefore, as the horizontal distance becomes smaller as shown in Figure 7, it is 


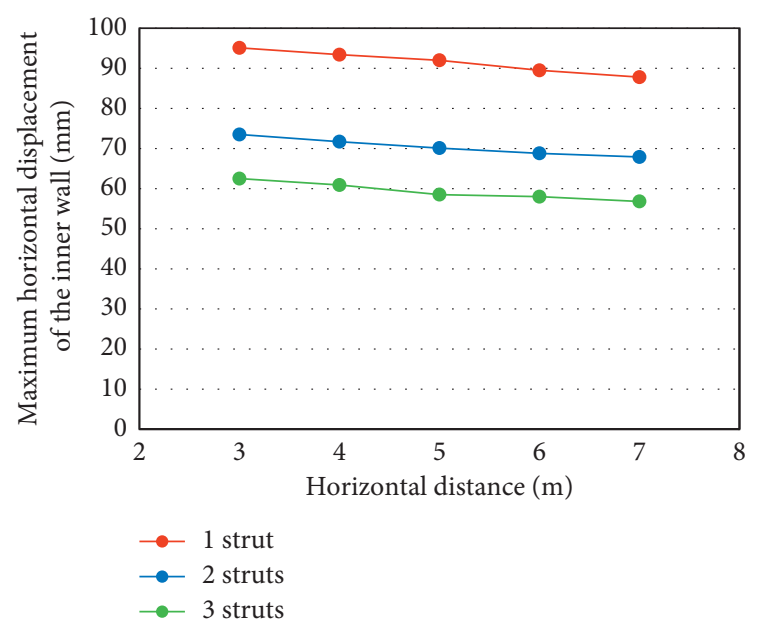

Figure 9: Relationship between the horizontal distance and the maximum horizontal displacement of the inner wall.

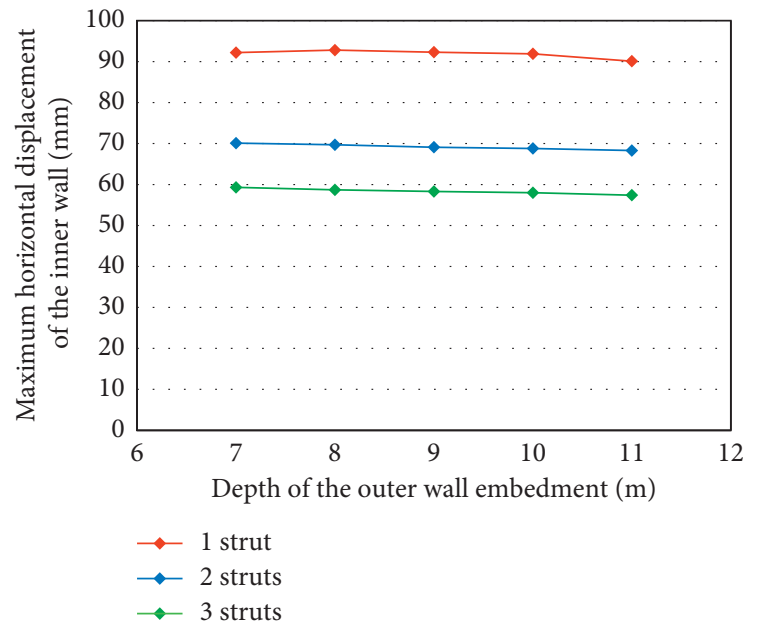

FIGURE 10: Relationship between the depth of the outer wall embedment and the maximum horizontal displacement of the inner wall.

considered that the lateral pressure of the inner wall becomes larger, which affects the displacement of the inner wall. Next, we focused on the guideline for controlling the displacement of the earth retaining wall in urban civil engineering to within $70 \mathrm{~mm}$. According to this guideline, the inner wall can be efficiently suppressed with a combination of 3 struts and 4 anchors when the horizontal distance is $3 \mathrm{~m}$ to $5 \mathrm{~m}$. In addition, the inner wall can be efficiently suppressed with a combination of 2 struts and 4 anchors when the horizontal distance is $6 \mathrm{~m}$ to $7 \mathrm{~m}$.

4.2.3. Influence of Depth of the Outer Wall Embedment. Figure 10 shows the relationship between the depth of the outer wall embedment and the maximum horizontal displacement of the inner wall. The depth of the outer wall embedment is changed from $7 \mathrm{~m}$ to $11 \mathrm{~m}$ in the clay of $N$ value 15 . The horizontal distance between the outer and inner walls is $5 \mathrm{~m}$. It can be seen that the maximum horizontal displacement of the inner wall increases as the depth of the outer wall embedment decreases. This indicates that the lateral pressure from the surrounding ground to the inner wall increases as the depth of the outer wall embedment decreases. Then, we focused on the guideline for controlling the displacement of the earth retaining wall in urban civil engineering to within $70 \mathrm{~mm}$. According to this guideline, the inner wall can be efficiently suppressed with a combination of 3 struts and 4 anchors when the depth of the outer wall embedment is $7 \mathrm{~m}$. In addition, the inner wall can be efficiently suppressed with a combination of 2 struts and 4 anchors when the depth of the outer wall embedment is $8 \mathrm{~m}$ to $11 \mathrm{~m}$.

\section{Conclusions}

In this study, the effect of the difference in soil properties on the behavior of earth retaining walls was investigated. The results of the study reveal the following:

(i) The wall deflection of the inner wall can improve by adopting the anchor support system that the anchors are hooked in the embedded part of the outer wall although the braced excavation with the struts is more effective to reduce the wall deflection.

(ii) Hybrid system with anchors and struts can sufficiently reduce the wall deflection of the inner wall to restrain the displacement of the earth retaining wall within $70 \mathrm{~mm}$, which is generally kept in the Japanese construction site of urban civil engineering.

(iii) Focusing on the displacement of the outer wall for each $N$-value, it is possible to efficiently suppress the displacement of the earth retaining wall with 2 struts and 4 anchors when the $N$-value of the sandy soil is 10 to 29 and the cohesive soil is 15 to 20 . Furthermore, it is possible to efficiently suppress the displacement of the earth retaining wall with 1 strut and 4 anchors when the $N$-value of the sandy soil is 30 or more and the cohesive soil is 20 or more.

(iv) Focusing on the horizontal displacement between the outer and inner walls, the inner wall can be efficiently suppressed with a combination of 3 struts and 4 anchors when the horizontal distance is $3 \mathrm{~m}$ to $5 \mathrm{~m}$. In addition, the inner wall can be efficiently suppressed with a combination of 2 struts and 4 anchors when the horizontal distance is $6 \mathrm{~m}$ to $7 \mathrm{~m}$.

(v) Focusing on the depth of the outer wall embedment, the inner wall can be efficiently suppressed with a combination of 3 struts and 4 anchors when the depth of the outer wall embedment is $7 \mathrm{~m}$. In addition, the inner wall can be efficiently suppressed with a combination of 2 struts and 4 anchors when the depth of the outer wall embedment is $8 \mathrm{~m}$ to $11 \mathrm{~m}$.

In addition, the tendency of displacement of the inner wall in urban areas due to changes in soil properties, the horizontal distance between the outer and inner walls, and the length of the outer wall was found through this study. 
Therefore, it can be suppressed below the standard for suppressing deformation in urban areas by applying the results of this article according to changes in these parameters at actual sites.

\section{Data Availability}

The data used to support the findings of this study are available from the corresponding author upon request.

\section{Conflicts of Interest}

The authors declare that there are no conflicts of interest regarding the publication of this article.

\section{Acknowledgments}

This work was supported by the Obayashi Foundation. The authors gratefully acknowledge their support.

\section{References}

[1] X. L. Jia, J. L. Xu, and Y. H. Sun, "Deformation analysis of reinforced retaining wall using separate finite element," Discrete Dynamics in Nature and Society, vol. 2018, Article ID 6946492, 9 pages, 2018.

[2] M. El-Emam, "Experimental and numerical study of at-rest lateral earth pressure od overconsolidated sand," Advances in Civil Engineering, vol. 2011, Article ID 524568, 12 pages, 2011.

[3] K. Rokugo, T. Kanda, H. Yokota, and N. Sakata, "Applications and recommendations of high performance fiber reinforced cement composites with multiple fine cracking (HPFRCC) in Japan," Materials and Structures, vol. 42, no. 9, pp. 1197-1208, 2009.

[4] H. Wen, J. J. Wu, J. L. Zou, X. Luo, M. Zhang, and C. Z. Gu, "Model tests on the retaining walls constructed from geobags filled with construction waste," Advances in Materials Science and Engineering, vol. 2016, Article ID 4971312, 13 pages, 2016.

[5] F. Gan, X. M. Ye, K. Yin, M. L. Li, and J. Bi, "Analysis of stress characteristics and the engineering application of the selfbalancing retaining wall," Advances in Materials Science and Engineering, vol. 2017, Article ID 24, 10 pages, 2017.

[6] A. H. Gandomi, A. R. Kashani, D. A. Roke, and M. Mousavi, "Optimization of retaining wall design using recent swarm intelligence techniques," Engineering Structures, vol. 103, pp. 72-84, 2015.

[7] Y. Yalcin, M. Orhon, and O. Pekcan, "An automated approach for the design of mechanically stabilized earth walls incorporating metaheuristic optimization algorithms," Applied Soft Computing, vol. 74, pp. 547-566, 2019.

[8] W. Zhang, Z. Hou, A. T. C. Goh, and R. Zhang, "Estimation of strut forces for braced excavation in granular soils from numerical analysis and case histories," Computers and Geotechnics, vol. 106, pp. 286-295, 2019.

[9] M. N. Houhou, F. Emeriault, and A. Belounar, "Three-dimensional numerical back-analysis of a monitored deep excavation retained by strutted diaphragm walls," Tunnelling and Underground Space Technology, vol. 83, pp. 153-164, 2019.

[10] R. N. Hwang and L. W. Wong, "Effects of preloading of struts on retaining structures in deep excavations," Geotechnical Engineering, vol. 49, no. 2, pp. 104-114, 2018.
[11] D. Raddatz, G. Suazo, and O. Taiba, "Strut reaction forces on a diaphragm wall: Comparison of numerical models, traditional methods and field measurements," Revista de la Construccion, vol. 15, no. 2, pp. 37-45, 2016.

[12] P. Jamsawang, P. Voottipruex, P. Tanseng, P. Jongpradist, and D. T. Bergado, "Effectiveness of deep cement mixing walls with top-down construction for deep excavations in soft clay: case study and 3D simulation," Acta Geotechnica, vol. 14, no. 1, pp. 225-246, 2019.

[13] Y. P. Dong, H. J. Burd, and G. T. Houlsby, "Finite-element analysis of a deep excavation case history," Géotechnique, vol. 66 , no. 1, pp. 1-15, 2016.

[14] L. Mu and M. Huang, "Small strain based method for predicting three-dimensional soil displacements induced by braced excavation," Tunnelling and Underground Space Technology, vol. 52, pp. 12-22, 2016.

[15] A. Lim, C. Y. Ou, and P. G. Hsieh, "A novel strut-free retaining wall system for deep excavation in soft clay: numerical study," Acta Geotechnica, 2019.

[16] A. Lim and C. Y. Ou, "Performance and three-dimensional analyses of a wide excavation in soft soil with strut-free retaining system," International Journal of Geomechanics, vol. 18, no. 9, Article ID 05018007, 2018.

[17] T. Nakai, M. M. Farias, D. Bastos, and Y. Sato, "Simulation of conventional and inverted braced excavations using subloading $t_{i j}$ model," Soils and Foundations, vol. 47, no. 3, pp. 597-612, 2007.

[18] J. Alam and S. A. Siddiquee, "A parametric study of anchored earth wall by finite element method," KSCE Journal of Civil Engineering, vol. 18, no. 7, pp. 2034-2042, 2014.

[19] C. Huang, W. Z. Ren, and L. W. Kong, "New mathematical modelling of stabilizing pile with prestressed tieback anchors," Mathematical Problems in Engineering, vol. 2013, Article ID 601508, 12 pages, 2013.

[20] Q. B. Zhan, X. J. Sun, C. Li et al., "Stability analysis and reinforcement of a high-steep rock slope with faults: numerical analysis and field monitoring," Advances in Civil Engineering, vol. 2019, Article ID 3732982, 8 pages, 2019.

[21] Z. Li, J. Wei, and J. Yang, "Stability calculation method of slope reinforced by prestressed anchor in process of excavation," Scientific World Journal, vol. 2014, Article ID 194793, 7 pages, 2014.

[22] J. Y. Han, W. Zhao, Y. Chen, P. J. Jia, and Y. P. Guan, “Design analysis and observed performance of a tieback anchored pile wall in sand," Mathematical Problems in Engineering, vol. 2017, Article ID 8524078, 23 pages, 2017.

[23] R. J. Finno and J. F. Roboski, “Three-dimensional responses of a tied-back excavation through clay," Journal of Geotechnical and Geoenvironmental Engineering, vol. 131, no. 3, pp. 273282, 2005.

[24] Z. Y. Orazalin, A. J. Whittle, and M. B. Olsen, "Three-dimensional analyses of excavation support system for the stata center basement on the MIT campus," Journal of Geotechnical and Geoenvironmental Engineering, vol. 141, no. 7, Article ID 05015001, 2015.

[25] M. Rouainia, G. Elia, S. Panayides, and P. Scott, "Nonlinear finite-element prediction of the performance of a deep excavation in boston blue clay," Journal of Geotechnical and Geoenvironmental Engineering, vol. 143, no. 5, Article ID 04017005, 2017.

[26] H.-L. Qu, H. Luo, H.-G. Hu, H.-Y. Jia, and D.-Y. Zhang, "Dynamic response of anchored sheet pile wall under ground motion: analytical model with experimental validation," Soil Dynamics and Earthquake Engineering, vol. 115, pp. 896-906, 2018. 
[27] Y. Huang, X. Xu, and W. Mao, "Numerical performance assessment of slope reinforcement using a pile-anchor structure under seismic loading," Soil Dynamics and Earthquake Engineering, vol. 129, Article ID 10, 2019.

[28] T. Shimomura, T. Ueno, and S. Takeda, Excavation and Earth Retaining-Design of Temporary Structures, Taisei Corporation, Tokyo, Japan, 2009.

[29] N. Iwata, M. Shahin, F. Zhang, T. Nakai, M. Niinomi, and Y. D. S. Geraldini, "Excavation with stepped-twin retaining wall: model tests and numerical simulations," in Geotechnical Aspects of Underground Construction in Soft Ground, pp. 655-661, CRC Press, Boca Raton, FL, USA, 2009.

[30] S. Sakuma, K. Maehara, T. Funatsu, A. Hamanaka, T. Sasaoka, and H. Shimada, "Analysis of the factors for displacement of earth retaining wall with twin-stepped construction," World Journal of Engineering and Technology, vol. 7, no. 1, pp. 114-121, 2019.

[31] Japan Society of Civil Engineers, Standard Specifications for Tunneling, Japan Society of Civil Engineers, Tokyo, Japan, 2016.

[32] T. Honda, "Setting method of joint element in earth retaining FEM analysis," in Soil and Bases, pp. 39-40, Soil Engineering Society, Tokyo, Japan, 1998.

[33] Nippon Steel \& Sumitomo Metal, Handbook of Construction Materials, Nippon Steel \& Sumitomo Metal, Tokyo, Japan, 2013.

[34] Product Dimensions of H-Shaped Steel, Marufuji Sheetpiling Co.,Ltd., Tokyo, Japan, 2018, http://www.mrfj.co.jp/product/ hgtku/.

[35] Japanese Geotechnical Society, Ground Anchor Design and Construction Standards, Japanese Geotechnical Society, Tokyo, Japan, 2012.

[36] Japanese Geotechnical Society, Ground Survey Method and Explanation, Japanese Geotechnical Society, Tokyo, Japan, 2013. 